\title{
A ESCOLHA DO LIVRO DIDÁTICO: UM INSTRUMENTO DE APOIO AO CORPO DOCENTE DO ENSINO FUNDAMENTAL
}

\author{
http://dx.doi.org/10.5902/2318133826738 \\ Sandra Regina Gonçalves Pimentel \\ Colégio Pedro II, Brasil. \\ Lúcia Regina Goulart Vilarinho \\ Fundação Cesgranrio, Brasil.
}

\begin{abstract}
Resumo
O objetivo deste estudo foi construir e validar um instrumento para ser utilizado por docentes dos anos iniciais do ensino fundamental em suas análises de livros didáticos. Tomou-se como referência posicionamentos do corpo docente do Colégio Pedro II, situados como especialistas dessa avaliação. Os subsídios das categorias de avaliação e seus indicadores foram retirados do projeto político-pedagógico do colégio e da literatura específica. $\mathrm{Na}$ análise das respostas dadas no questionário, que avaliou o instrumento, verificou-se uma ampla aceitação do instrumento como apoio à tarefa de escolher o livro didático.

Palavras-chave: avaliação, livro didático, instrumento de avaliação, ensino fundamental.
\end{abstract}

\section{TEXTBOOK SELECTION: A SUPPORT TOOL FOR THE PRIMARY EDUCATION TEACHING STAFF}

\section{Abstract}

The studys objective was to build and validate an instrument to be used by primary education teachers in their textbook analysis. A qualified teaching staff of the Pedro II School considered as experts were taken as reference for this evaluation. The subsidies and indicators of the evaluation categories were obtained from the schools political-pedagogical project and the specific literature. In the analysis of the results of the questionnaire that evaluated the instrument, a broad acceptance of the tool as support for textbook selection was verified.

Key-words: evaluation, textbook, evaluation tool, primary education. 


\section{Uma reflexão sobre o programa nacional do livro didático}

Programa Nacional do Livro Didático - PNLD - é, segundo diversos autores
(Höfling, 2000; Britto, 2011; Silva, 2012), um programa federal de aquisição
e distribuição de material didático de importância indiscutível, que vem sendo consolidado, expandido e aprimorado ao longo dos últimos anos. Tem como objetivo subsidiar o trabalho pedagógico dos professores pela distribuição gratuita de coleções de livros didáticos aos alunos da educação básica, seguindo o seguinte fluxo: 0 Ministério da Educação, avalia as obras e publica um guia de livros didáticos com resumos das coleções aprovadas. Em seguida, o guia é distribuído nas escolas, que escolhem, entre os títulos disponíveis, os que atendem ao seu projeto político pedagógico. O programa é executado em ciclos trienais alternados. A cada ano, o Fundo Nacional de Desenvolvimento Econômico - FNDE - recebe os livros já analisados pela equipe avaliadora do PNLD e os distribui para todos os alunos de determinada etapa de ensino, repondo e complementando os livros reutilizáveis para outras etapas (Brasil, 2012).

Desta forma, o programa deixa de ter um caráter assistencial e adquire, pelos parâmetros constitucionais, um caráter universal, obrigatório, voltado para aqueles que têm direito ao acesso à educação. (Höfling, 2000). Desde sua origem (1985), tem sofrido muitas críticas, sendo que uma delas foi bastante positiva, pois levou a mudança significativa na medida em que "os livros didáticos passaram a ser escritos, via de regra, por professores com formação nas áreas, sobre as quais escreviam e, de um modo geral, em exercício nas séries para as quais seus livros eram destinados" (Silva, 2012, p. 809).

Para Britto (2011), o PNLD foi aperfeiçoado na década de 1990, quando todos os alunos do ensino fundamental regular em escolas públicas passaram a receber os livros e quando, também, passou a ocorrer a avaliação pedagógica para assegurar a qualidade do material adquirido. Entre os anos de 1993 e 1994 foram definidos critérios de avaliação dos livros didáticos com a publicação Definição de critérios para avaliação dos livros didáticos.

Até chegarem às escolas e serem avaliados pela equipe pedagógica, os livros didáticos passam por algumas etapas: a) inscrição das editoras que desejam participar do edital aberto pelo MEC; b) triagem e a avaliação dos livros recebidos pelo MEC que os encaminha para o Instituto de Pesquisas Tecnológicas da Universidade de São Paulo, para avaliação da qualidade técnica. Após esta análise são encaminhados à Secretaria de Educação Básica, que é o órgão responsável pela avaliação pedagógica; c) confecção do guia do livro didático, documento que contém as avaliações dos livros aprovados, publicadas pelo FNDE. Este material é enviado às escolas cadastradas no censo escolar. É nesta fase que os professores e demais integrantes da equipe pedagógica fazem as análises das resenhas de cada coleção e selecionam as que estão mais de acordo com o projeto político-pedagógico da escola, com os alunos e professores e, ainda, com a realidade sociocultural das instituições. Após esse processo a escola deve apontar sua escolha e fazer o pedido de duas obras para cada ano e disciplina; d) produção em série dos livros: nesta etapa o FNDE inicia o processo de negociação com as editoras, firma o contrato, informando a quantidade e os locais de entrega. A produção é supervisionada por técnicos do FNDE; e) distribuição dos livros, realizada pelas editoras às escolas por contrato com o FNDE e a Empresa Brasileira de Correios e Telégrafos. 
Segundo Di Giorgi et al. (2014), apesar de ser aperfeiçoado com frequência, o PNLD ainda sofre críticas, principalmente em relação às obras selecionadas que chegam às escolas. Isso pode ocorrer porque se atribui ao livro didático a função de formação docente mas, ao mesmo tempo em que assume o papel de condutor das atividades pedagógicas, se torna um obstáculo na aprendizagem dos alunos, na medida em que os estes têm dificuldades de compreender o seu conteúdo, com aulas eminentemente teóricas, sem qualquer atividade prática que prenda a sua atenção (Oliveira, 2014).

Silva (2012) afirma que o livro didático está "consagrado em nossa cultura escolar" e "tem a primazia entre os recursos didáticos utilizados na grande maioria das salas de aula do ensino básico" (p. 806). Além de ser um instrumento de informação para professores, é considerado elemento importante para aumentar o capital cultural dos alunos e também o de suas famílias (Di Giorgi et al., 2014). Mas, apesar da importância que apresenta no contexto escolar, em qualquer nível de ensino, há sempre críticas em relação a aspectos os mais distintos que fazem parte da sua produção, como conteúdo, formato, ideologias. Em última instância, as críticas remetem para a questão da qualidade do material didático-pedagógico.

Silva (1996, p. 11) considera que "à perda crescente da dignidade do professor do professor brasileiro contrapõe-se o lucro indiscutível e estrondoso das editoras de livros didáticos". Bezerra (2006, p. 31), afirma que "os materiais didáticos rapidamente deixaram de ser obras de referência, como haviam sido até então e passaram a orientar e conduzir a ação docente.

É neste complexo cenário que surge a necessidade de se pensar um instrumento de apoio aos docentes, a ser usado no momento em que tratam da seleção do livro didático. Foi este o objetivo do presente estudo: construir, validar e apresentar um instrumento que possa ser utilizado por docentes dos anos iniciais do ensino fundamental, em suas análises de livros didáticos oriundos das indicações emanadas do PNLD.

\section{O contexto de apoio à construção do instrumento}

Um caminho diferente, na escolha do livro didático, é traçado por Oliveira (2014), ao sugerir que os docentes utilizem os livros como apoio e não como guia de suas práticas pedagógicas. Para este autor é importante "o uso de outros recursos didáticos para facilitar a aprendizagem dos alunos, como também, novas metodologias de uso dos livros didáticos" (p. 3). Tendo este princípio como norte, considerou-se importante o suporte de professores de um colégio cuja seleção para o seu ingresso no magistério fosse rigorosa. Assim, escolheu-se o corpo docente do Colégio Pedro II - Ensino Fundamental 1ํㅡㄴ segmento, que, além de passar pelo crivo da entrada, tem possibilidade de fazer uma carreira docente ao realizar cursos de especialização, mestrado ou doutorado.

Este corpo docente faz parte do campus Humaitá I, fundado em 1985 e situado na zona sul da cidade do Rio de Janeiro. Atualmente atende crianças de cinco a 11 anos, distribuídas nos anos referentes ao $1^{\circ}$ segmento do ensino fundamental. É formado por professores concursados efetivos e também por professores contratados (Lino, 2015).

Recentemente, com a lei n. 12.677/2012, o Colégio Pedro II foi equiparado aos institutos federais, o que the deu maior visibilidade no âmbito da educação básica. 
Para este corpo docente inúmeras questões podem ser levantadas em relação à seleção dos livros didáticos. Entre essas cabe destacar algumas registradas em entrevistas informais ${ }^{1}$ : a) o número elevado de opções para a escolha; b) pouco tempo para olhar e analisar todas as obras com calma, de modo a poder compará-las e escolher o critério da equipe; c) o fato de que alguns livros nem são analisados pela equipe; d) dificuldade para distribuir as obras entre os professores para que todos possam opinar na escolha do material; e) a escolha feita antecipadamente, sem conhecer as turmas e, nem sempre, a decisão é a mais acertada; f) a escolha de uma única coleção de livros didáticos para todos os campi, não respeitando as individualidades; g) a ausência de um livro virtual ou real para análise, fazendo com que as editoras mais organizadas, ou com setor de marketing mais eficaz, saiam na frente; h) o fato de que cada livro tem um tipo de organização, portanto é difícil escolher um e descartar o outro; i) o consenso como critério de escolha do livro didático nem sempre possibilita a melhor escolha.

Tais registros denotam uma preocupação com a avaliação do livro didático e, assim, entendeu-se que seria oportuna a realização de um estudo avaliativo capaz de oferecer subsídios a essa prática. Escolheu-se, então, o campus Humaitá I como contexto de apoio ao estudo.

\section{Desenvolvimento do estudo}

Definidos o contexto e os participantes do estudo, foi construído um projeto avaliativo capaz de dar conta do objetivo mencionado anteriormente

Bases pedagógicas do instrumento

O Colégio tem como eixos norteadores de suas ações princípios filosóficos e metodológicos que respeitam as características referentes à faixa etária dos anos iniciais do $1^{\circ}$ segmento do ensino fundamental. Este conjunto de princípios e diretrizes orientam as ações pedagógicas da escola e encontram-se no seu projeto político-pedagógico (Colegio Pedro II, 2002). Tal documento baseia-se nos parâmetros curriculares nacionais - 1a a 4⿳亠丷a séries (PCN, Brasil, 1997).

Para Veiga (2004), o projeto político-pedagógico está relacionado com a organização do trabalho pedagógico, seja na dimensão da organização da escola ou na organização da sala de aula, respeitando o contexto social em sua totalidade.

Sabendo-se que os docentes valorizam tais princípios, a primeira parte do trabalho foi estudar e selecionar quais deles poderiam ser transformados em categorias avaliativas e como desdobrá-las em indicadores.

As categorias de avaliação se referem aos aspectos macro que se busca avaliar e, no presente caso, foram três: aspectos filosófico-educacionais, aspectos didáticometodológicos e aspectos materiais. Os indicadores constituem os desdobramentos desses aspectos, que devem estar presentes no objeto em análise. Na seleção dos aspectos filosófico-educacionais tomou-se como referência aspectos retirados do projeto político-pedagógico (Colégio Pedro II, 2002). Na escolha das demais categorias aspectos didático-metodológicos e materiais - houve o subsídio de leituras: Vilarinho e Silva (2015), Silva (2012), Silva (2007), Freitag, Costa e Motta (1997) e Choppin (2004).

1 As entrevistas foram realizadas de modo informal com dez professoras dos anos iniciais do ensino fundamental.

Regae: Rev. Gest. Aval. Educ.

Santa Maria

v. 6

ก. 13

Set./dez. 2017

p. $37-52$ 
Assim, foi construído um quadro inicial, submetido à avaliação de um grupo de cinco professores que sugeriram mudanças em sua estrutura, fundamentadas em aspectos encontrados no projeto político-pedagógico do Colégio. Considerou-se que esses docentes, por já concretizarem a tarefa da seleção de livros didáticos e usarem os mesmos diariamente nas salas de aula, seriam as respondentes mais adequadas para avaliar o quadro. Este quadro deu origem ao quadro de categorias, que é um aspecto obrigatório em um estudo avaliativo, apresentado na seção subsequente.

\section{Procedimentos metodológicos}

Definiu-se, em conformidade com a teoria da avaliação, que a abordagem mais pertinente à proposta seria a baseada em especialistas, no caso os docentes do $1^{\circ}$ segmento do ensino fundamental, pela experiência que trazem consigo. Para Worthen, Sanders e Fitzpatrick (2004) este tipo de abordagem "depende basicamente dos conhecimentos específicos de um profissional para julgar uma instituição, um programa, um produto ou uma atividade" (p. 179). Em outras palavras, baseia-se nos conhecimentos técnico-profissionais de especialistas, convidados a julgar a qualidade de um determinado objeto.

Qualquer avaliação, para ser transparente e objetiva, precisa apoiar-se em critérios previamente estabelecidos. considerando este princípio, estabeleceu-se o quadro de critérios, anteriormente mencionado, no qual foram indicado as categorias de avaliação e seus indicadores.

Quadro 1 -

Categorias de avaliação e seus indicadores.

\begin{tabular}{|c|c|}
\hline Categoria & Indicadores \\
\hline \multirow{8}{*}{$\begin{array}{l}\text { Aspectos filosófico- } \\
\text { educacionais definidos } \\
\text { pelos docentes do } \\
\text { Colégio Pedro II }\end{array}$} & Uso de situações contextualizadas \\
\hline & Perspectiva interdisciplinar \\
\hline & $\begin{array}{l}\text { Vivência cidadã e participação na construção de uma sociedade justa e } \\
\text { democrática }\end{array}$ \\
\hline & Postura investigativa estimulando o levantamento de hipóteses. \\
\hline & Respeito a si mesmo e aos outros \\
\hline & Desenvolvimento da autonomia. \\
\hline & Estímulo ao levantamento de hipóteses \\
\hline & Ausência de situações de preconceito (raça, gênero, religiosa) \\
\hline \multirow{11}{*}{$\begin{array}{l}\text { Aspectos didático- } \\
\text { metodológicos }\end{array}$} & Organização das sequências didáticas de forma flexível \\
\hline & Utilidade das estratégias de ensino \\
\hline & Planejamento das aulas \\
\hline & Conexão entre objetivos e conteúdos \\
\hline & Respostas no livro do professor \\
\hline & Ampliação dos recursos cognitivos \\
\hline & Mobilização de conhecimentos prévios do aluno \\
\hline & Construção de conceitos \\
\hline & Clareza dos conteúdos \\
\hline & Quantidade de atividades/exercícios por capítulo \\
\hline & Participação do aluno em sala de aula \\
\hline
\end{tabular}




\begin{tabular}{|l|l|}
\hline \multirow{4}{*}{ Aspectos materiais } & Atividades desafiadoras \\
\cline { 2 - 2 } & Diversidade e qualidade dos textos literários \\
\hline & Associação entre texto e imagem \\
\cline { 2 - 2 } & Relação entre imagem e conceito \\
\cline { 2 - 2 } & Adequação da linguagem \\
\cline { 2 - 2 } & Formatação gráfica \\
\cline { 2 - 2 } & Clareza dos enunciados \\
\hline
\end{tabular}

Fonte: As autoras (2017).

Da análise da literatura pedagógica voltada para a problemática do livro didático depreendeu-se que essas três categorias são as que, necessariamente, devem ser consideradas na avaliação pedagógica desse recurso.

Em seguida, selecionaram-se os especialistas, que teriam como tarefa analisar e validar a ficha de avaliação derivada deste quadro, cujo objetivo é auxiliar o professor na escolha de livros didáticos destinados aos anos iniciais do ensino fundamental. Esses especialistas, todos vinculados ao campus Humaitá I, somavam um total de 48 docentes, não incluídos os que se encontravam de licença. Para eles foi encaminhado o convite, solicitando que respondessem à avaliação, tendo se obtido resposta de 29 especialistas.

\section{$O$ instrumento de avaliação}

Com base no quadro de critérios foi possível construir um instrumento chamado de ficha de avaliação, orientado para ajudar aos docentes em sua tarefa de análise do livro didático.

Como esta ficha deveria passar, inicialmente, por um processo de validação, foi necessário encaminhá-la a outro grupo de especialistas, para que pudessem realizar tal tarefa. Este encaminhamento demandou a elaboração de um questionário, composto de perguntas abertas e fechadas, cujo objetivo era ajudar na validação

Esta validação foi conduzida por especialistas em educação e avaliação e focalizou a validade do conteúdo do instrumento no sentido de medir realmente aquilo a que se propõe medir (Martins, 2006). Neste sentido, solicitou-se aos especialistas responderem à pergunta: o instrumento abarca o conteúdo pretendido? Como lhes foi solicitada a validação de conteúdo, as especialistas, além do questionário e da ficha de avaliação, receberam recortes do projeto de estudo referentes aos seguintes elementos: objetivo e questão de estudo e quadro de critérios.

Desta validação surgiram diversos comentários relacionados a aspectos positivos e negativos e o instrumento foi reelaborado, ficando com o seu formato definitivo para aplicação com os 29 docentes especialistas.

\section{Resultados da avaliação}

Todos os especialistas participantes da avaliação atuavam no $1^{\circ}$ segmento do ensino fundamental, em diferentes séries. A maior parte dos docentes efetivos (12) possui título de mestre e dois o título de doutorado. Em relação aos professores contratados apenas um possui mestrado e nenhum possui doutorado, sendo a maior parte (quatro) graduados e três possuindo especialização. Vale lembrar que duas docentes efetivas, que possuem pós-graduação lato sensu, estão cursando mestrado, uma docente com mestrado é doutoranda na área de educação, duas docentes contratadas estão cursando 
mestrado e uma docente contratada já possui título de mestre. Estes dados confirmam a exigência do Colégio Pedro II em relação à titulação de seus docentes, configurando um quadro de professores qualificado, tanto no conjunto dos efetivos, quanto de contratados.

A ficha de avaliação, com três categorias avaliativas, ficou assim composta: nos aspectos filosófico-educacionais foram incluídas nove indagações; na segunda categoria aspectos didático-metodológicos, inseridas 16 perguntas; e na terceira, aspectos materiais, incorporadas sete questões. Assim, a Ficha contabilizou 32 perguntas, todas solicitando inicialmente uma resposta previamente definida, escolhida no limite de três opções: sim; não; parcialmente.

A primeira categoria, Aspectos filosófico-educacionais, foi elaborada a partir do projeto político-pedagógico do Colégio Pedro II, publicado no ano de 2000. A segunda, Aspectos didático-metodológicos, é composta por indicadores retirados de um instrumento já validado (Silva, 2015), considerados relevantes para um livro didático. A terceira categoria - Aspectos materiais - foi retirada do exame da literatura.

Segundo o Programa Nacional do Livro Didático PNLD, 2008 (Brasil, 2007) deve-se garantir ao livro uma organização clara, coerente e funcional. As imagens não devem estar presentes no livro sem que tenham uma função e sem que estejam contextualizas e adequadas ao público a que se destina. $O$ mesmo deve acontecer com a formatação gráfica, tipologias, tamanhos de colunas e alinhamento gráfico. Foi a partir desses conceitos que optou-se por incluir a terceira categoria, Aspectos materiais, ao instrumento validado neste estudo.

Todas as categorias foram avaliadas atendendo aos padrões previamente definidos, conforme apresentado a seguir, no resultado global.

Tabela 1 -

Avaliação global das categorias.

\begin{tabular}{|l|c|c|c|}
\hline \multicolumn{1}{|c|}{ Categorias } & Sim & Parcialmente & Não \\
\hline $\begin{array}{l}\text { a) Aspectos filosófico- } \\
\text { educacionais }\end{array}$ & 23 & 6 & - \\
\hline $\begin{array}{l}\text { b) Aspectos didático- } \\
\text { metodológicos }\end{array}$ & 21 & 8 & 1 \\
\hline c) Aspectos Materiais & 24 & 4 & - \\
\hline
\end{tabular}

Fonte: As autoras (2017).

As perguntas que fizeram parte do instrumento avaliado por esses especialistas, já com as alterações propostas por eles, são a seguir apresentadas, lembrando-se que em cada uma delas o respondente tinha de optar por uma das três opções: sim, parcialmente e não e fazer, quando fosse o caso, comentários a respeito da opção escolhida.

Quadro 2 -

Perguntas do instrumento de avaliação.

Avaliação dos aspectos filosófico-educacionais

1) Uso de situações contextualizadas $\quad$ O livro apresenta situações em contextos relacionados ao universo dos alunos? 


\begin{tabular}{|c|c|}
\hline 2) Perspectiva interdisciplinar & $\begin{array}{l}\text { O livro apresenta situações que oferecem uma } \\
\text { perspectiva interdisciplinar, mobilizando } \\
\text { conceitos de diferentes campos do } \\
\text { conhecimento, de forma articulada? }\end{array}$ \\
\hline $\begin{array}{lcccc}\text { 3) Vivência cidadã } & \text { e participação } & \text { na } \\
\text { construção de uma } & \text { sociedade justa } & \text { e } \\
\text { democrática } & & & & \\
\end{array}$ & $\begin{array}{l}\text { O livro propõe atividades que promovam a } \\
\text { cidadania? }\end{array}$ \\
\hline 4) Estímulo ao levantamento de hipóteses & $\begin{array}{l}\text { O livro promove, por meio de textos e atividade, } \\
\text { uma postura investigativa? }\end{array}$ \\
\hline 5) Respeito a si mesmo e aos outros & $\begin{array}{l}\text { O livro estimula ações que geram respeito ao } \\
\text { próximo e a si mesmo? }\end{array}$ \\
\hline 6) Respeito às diferenças & $\begin{array}{l}\text { O livro respeita as diversidades em todos os } \\
\text { aspectos, sejam elas raciais, religiosas, de } \\
\text { gênero, etc? }\end{array}$ \\
\hline 7) Desenvolvimento da autonomia & $\begin{array}{l}\text { O livro propõe atividades que possibilitam ao } \\
\text { aluno construir conceitos e opiniões? }\end{array}$ \\
\hline 8) Aprendizagem individual & $\begin{array}{l}\text { O livro propõe atividades que possibilitam o } \\
\text { aluno a estudar e aprender sozinho? }\end{array}$ \\
\hline 9) Trabalho colaborativo & $\begin{array}{l}\text { O livro propõe atividades que proporcionam o } \\
\text { trabalho colaborativo para a construção e } \\
\text { desenvolvimento da autonomia? }\end{array}$ \\
\hline \multicolumn{2}{|l|}{ Avaliação dos aspectos didático-metodológicos } \\
\hline 10) Organização das sequências didáticas & $\begin{array}{l}\text { O livro apresenta os conteúdos didaticamente } \\
\text { ordenados, numa sequência lógica? }\end{array}$ \\
\hline $\begin{array}{l}\text { 11) Utilidade das estratégias de ensino- } \\
\text { aprendizagem }\end{array}$ & $\begin{array}{l}\text { O livro propõe estratégias de ensino relevantes } \\
\text { ao processo de construção do conhecimento? }\end{array}$ \\
\hline 12) Planejamento das aulas & $\begin{array}{l}\text { O livro apresenta elementos que auxiliam e } \\
\text { instrumentalizam o professor na elaboração de } \\
\text { seu plano de aula? }\end{array}$ \\
\hline 13) Contribuição do manual & $\begin{array}{l}\text { O livro apresenta um manual que apresente } \\
\text { outras sugestões de atividades ou novas } \\
\text { explorações de conteúdos? }\end{array}$ \\
\hline 14) Conexão entre objetivos e conteúdos & $\begin{array}{l}\text { O livro está alinhado com os objetivos de } \\
\text { aprendizagem da proposta curricular da } \\
\text { disciplina? }\end{array}$ \\
\hline 15) Respostas no livro do professor & $\begin{array}{l}\text { O livro do professor apresenta as respostas } \\
\text { que podem auxiliar o professor na sua prática } \\
\text { docente? }\end{array}$ \\
\hline 16) Atividades práticas & $\begin{array}{l}\text { O livro apresenta propostas de atividades } \\
\text { práticas em sala, ou projetos, } \\
\text { relacionados aos conteúdos ensinados? }\end{array}$ \\
\hline $\begin{array}{l}\text { 17) Mobilização de conhecimentos prévios do } \\
\text { aluno }\end{array}$ & $\begin{array}{l}\text { O livro apresenta atividades que valorizam o } \\
\text { conhecimento do aluno adquirido fora do } \\
\text { âmbito escolar? }\end{array}$ \\
\hline
\end{tabular}




\begin{tabular}{|c|c|}
\hline 18) Construção de conceitos & $\begin{array}{l}\text { O livro promove a construção de conceitos } \\
\text { adequados ao nível de desenvolvimento do } \\
\text { aluno? }\end{array}$ \\
\hline 19) Ampliação dos recursos cognitivos & $\begin{array}{l}\text { O livro mobiliza operações mentais que } \\
\text { extrapolam a automação e a memorização? }\end{array}$ \\
\hline $\begin{array}{l}\text { 20) Quantidade de atividades/exercícios por } \\
\text { capítulo }\end{array}$ & $\begin{array}{l}\text { O livro possui quantidade de atividades } \\
\text { (exercícios por capítulo), adequada aos } \\
\text { objetivos da disciplina? }\end{array}$ \\
\hline 21) Participação do aluno em sala de aula & $\begin{array}{l}\text { O livro propõe atividades que promovam a } \\
\text { participação do aluno durante as aulas? }\end{array}$ \\
\hline 22) Atividades desafiadoras & $\begin{array}{l}\text { O livro é desafiador para o público a que se } \\
\text { destina, considerando o seu nível cognitivo? }\end{array}$ \\
\hline 23) Sistematização de conteúdo & $\begin{array}{l}\text { O livro apresenta sistematização do conteúdo } \\
\text { dado em sala de aula? }\end{array}$ \\
\hline $\begin{array}{l}\text { 24) Diversidade e qualidade dos textos } \\
\text { literários }\end{array}$ & $\begin{array}{l}\text { O livro apresenta textos de boa qualidade e de } \\
\text { diferentes gêneros literários? }\end{array}$ \\
\hline 25) Propostas curriculares adaptadas & $\begin{array}{l}\text { O livro apresenta propostas de atividades } \\
\text { adaptadas, que promovam acesso à } \\
\text { informação aos alunos da educação inclusiva? }\end{array}$ \\
\hline \multicolumn{2}{|l|}{ Avaliação dos aspectos materiais } \\
\hline 26) Associação entre texto e imagem & $\begin{array}{l}\text { O livro faz associações coerentes entre os } \\
\text { textos e as imagens que os representam? }\end{array}$ \\
\hline 27) Relação entre imagem e conceito & $\begin{array}{l}\text { O livro relaciona imagem e conceito de forma } \\
\text { coerente? }\end{array}$ \\
\hline 28) Clareza dos enunciados & $\begin{array}{l}\text { Os enunciados estão redigidos de maneira } \\
\text { clara? }\end{array}$ \\
\hline 29) Adequação da linguagem & $\begin{array}{l}\text { O livro apresenta linguagem adequada ao perfil } \\
\text { dos alunos? }\end{array}$ \\
\hline 30) Formatação gráfica & $\begin{array}{l}\text { O livro possui apresentação visual clara e } \\
\text { estimulante (uso de fontes, imagens, cores e } \\
\text { quantidade de ilustrações adequadas)? }\end{array}$ \\
\hline 31) Qualidade do material & $\begin{array}{l}\text { O livro apresenta um material físico de } \\
\text { qualidade que garanta a sua durabilidade? }\end{array}$ \\
\hline 32) Adequação do título & $\begin{array}{l}\text { O livro apresenta um título adequado ao seu } \\
\text { conteúdo? }\end{array}$ \\
\hline
\end{tabular}

Além da quantificação das respostas no questionário diversos especialista registraram comentários. Alguns deles são a seguir transcritos e compatibilizados com a fundamentação pedagógica que subsidiou a construção do instrumento. Em relação aos comentários sobre os aspectos filosófico-educacionais selecionaram-se dois registros, 0 do respondente $\mathrm{R} 4$ e o do $\mathrm{R} 29$.

R4 - Os livros didáticos são utilizados em todo o Brasil, por isso, são muito gerais, o que dificulta relacionar as situações apresentadas aos universos dos alunos. Acaba cabendo ao docente fazer esta relação durante as

v. 6

n. 13

Set./dez. 2017 
aulas. Poucos livros articulam os conceitos de diferentes campos de conhecimento. Eu tenho que usar 5 livros: história, geografia, ciências, língua portuguesa e matemática, ou seja, os conhecimentos nos livros didáticos são disciplinares.

No projeto político-pedagógico do Colégio (Colégio Pedro II, 2002), afirma-se que, entre os princípios pedagógicos eleitos para nortear o ensino fundamental $1^{\circ}$ segmento, está o "estabelecimento de relações entre a vida cotidiana e a vida escolar, associando as experiências vividas pelo aluno ao campo conceitual trabalhado na escola" (p. 74). É difícil contemplar este princípio com todos os alunos da turma. Talvez, a perspectiva aqui deva ser genérica, prevendo-se contemplar alguns alunos em uma atividade e em outra atingir outros discentes. Não se pode esquecer que um projeto político-pedagógico tem um cunho genérico, que busca atender a maioria dos alunos.

R29 - Eu colocaria, no item 6, Respeito às Diferenças como categoria de análise. Assim, trabalharíamos com a ideia de diversidade. Acho que ausência de preconceito não contempla o que queremos buscar em um livro, que trabalhe com as diferenças e respeito a diversidade, seja ela de raça, gênero, orientação ou deficiência. No Item 3 eu não concordo com o termo "sociedade justa". O que é justo para um, pode não ser para o outro. Tiraria isso e deixaria somente uma sociedade democrática, que não deixa dúvidas.

O político-pedagógico do Colégio (Colégio Pedro II, 2002) tem como outro princípio pedagógico: o "exercício da vivência cidadã visando à participação efetiva na construção de uma sociedade justa e democrática" (p. 74). Considerou-se, então, pertinentes os comentários de R29. As suas indicações foram aceitas, sendo incorporado o respeito às diferenças, item 6, e incluída a palavra democrática, item 3. Vale lembrar que os princípios pedagógicos do Colégio são divulgados para rechaçar

a perspectiva redutora que concebe o aluno como um modelo abstrato de criança, agente receptor de informações e conteúdos descontextualizados, que vê a escola como o único espaço produtor de conhecimento, o processo de ensino-aprendizagem exclusivamente como o de transmissão/ recepção de conhecimento e o professor, enquanto seu representante, como único depositário desse conhecimento (p. 74).

Sobre os aspectos didático-metodológicos foram retiradas duas respostas, a de $\mathrm{R} 20$ e a de $\mathrm{R} 21$, a seguir apresentadas.

R20 - Quanto à organização das sequências didáticas, não considero que exista uma única sequência lógica (item 10). Creio que este item exige do professor uma certa experiência prática em sala de aula. Um professor inexperiente terá dificuldade em avaliar esse item.

A contribuição de R20 é bastante plausível. O que é uma sequência lógica? Cada professor pode ver a sequência de uma determinada maneira, portanto, não existe uma única sequência lógica. Talvez aqui seja importante ajustar a avaliação para uma perspectiva genérica, pois é feita uma pergunta: o livro apresenta os conteúdos didaticamente ordenados, numa sequência lógica? Ou seja, há uma ordem na organização dos conteúdos? Esta sequência lógica é a que eu aprovo? E para 
complementar, será preciso que o professor avaliador tenha certa experiência para poder compreender o livro como um todo, com as suas sequências.

A necessidade desta experiência está afirmada no político-pedagógico do Colégio (Colégio Pedro II, 2002, p. 74):

cabe ao professor, além do domínio do conteúdo e do reconhecimento da criança como o sujeito da construção de seu próprio conhecimento, o agir, articulando e promovendo situações e atividades (significativas, interessantes, variadas e tecnicamente fundamentadas) que estimulem e desafiem a criança a conhecer e a desenvolver-se.

Na manifestação de R21,

R21 - Sugiro que o questionário aborde a existência de projetos pedagógicos exequíveis, qualitativos, cuja realização possibilite a mobilização dos conceitos trabalhados Proposta: Atividades teóricopráticas: O livro apresenta propostas de atividades práticas em sala, ou projetos, relacionados com os conteúdos ensinados e que possibilitem a mobilização de tais conteúdos? O livro apresenta atividades práticas interdisciplinares ou projetos pedagógicos que articulem os conteúdos ensinados?,

se expressa a importância de o livro trabalhar com projetos que mobilizem os conceitos estudados, de forma teórico-prática e com atividades interdisciplinares. Isto implica em aceitar que o $1^{\circ}$ segmento construa uma metodologia que compreenda "um conjunto de princípios e pressupostos teóricos, cuja aplicação confere determinado rumo e determinadas abordagens à imediatização da prática pedagógica" [...] a metodologia "refere-se à lógica de estruturação e abordagens dos conteúdos (conhecimentos). A escola, preocupada com a construção do conhecimento e com a formação de valores, deve estabelecer procedimentos metodológicos comuns" (Colégio Pedro II, 2002, p. 69). Em outras palavras, trabalhar com projetos implica aceitar uma metodologia que tenha um rumo, seguindo uma determinada lógica e que possa ser aplicada com finalidades que ultrapassem uma sala de aula.

Quanto aos comentários sobre os aspectos materiais dos livros, destaca-se o apresentado por R27:

R27 - Acho que poderia incluir a avaliação da quantidade de atividades por páginas e se há espaço suficiente para o aluno escrever suas respostas (no caso dos livros consumíveis). No caso dos livros não consumíveis, verificar se os enunciados são concisos para o caso de o aluno precisar copiá-los.

A manifestação também foi percebida como pertinente, pois na ficha de avaliação não há uma pergunta que indague a questão da quantidade. Não se concorda, no entanto, com uma avaliação por página, pois a quantidade de atividades deve estar atrelada ao conteúdo apresentado. 


\section{Avaliação do instrumento como apoio na escolha do livro didático}

Indagou-se aos 29 especialistas se o instrumento auxilia na escolha dos livros didáticos apresentados. Tabulados os dados, observou-se que 22 respondentes responderam positivamente e sete assinalaram que parcialmente. Não houve indicação da opção negativa.

Também foram feitos alguns registros, dos quais destacamos quatro:

R3 - Sim, pois aborda todos aspectos imprescindíveis para a adequação de um livro didático ao PPI do colégio.

R15 - Parcialmente. Existem problemas nas publicações que só são perceptíveis com a experiência de uso efetivo no dia a dia.

R17 - Sim. Considero o instrumento um bom orientador no momento de avaliação para a escolha do livro didático.

R27 - Mudaria pequenas coisas, sinalizadas ao longo dessa ficha.

Verifica-se, então, que os comentários são positivos em relação ao instrumento como apoio à escolha do livro didático.

Por último perguntou-se sobre a adequação do instrumento ao objetivo para o qual foi proposto. Os dados indicam que os respondentes consideram o instrumento adequado ao objetivo para o qual foi proposto - auxiliar o docente na escolha do livro didático. Eles sinalizaram excelente (17) e bom (10), o que totalizou 27 especialistas considerando 0 instrumento adequado.

Por fim, foi dado um espaço para que os participantes escrevessem os aspectos negativos e positivos que tinham percebido no instrumento. Foram apresentados 27 comentários positivos, dos quais selecionamos três:

R20 - Já participei de avaliações de livros didáticos para a escolha dos livros didáticos da série em que trabalhava e não sabia que critérios utilizar. Esse instrumento teria sido muito útil.

R24 - O instrumento apresenta linguagem clara e bastante objetiva. Além disso, consegue elencar as categorias principais para o professor e a equipe pedagógica poderem avaliar com precisão os livros didáticos apresentados e, posteriormente, poderem escolher aquele que realmente será útil e eficaz á proposta do Colégio.

R27 - Bem detalhado, faz o professor pensar sobre os diversos aspectos envolvidos na escolha do livro didático. Acho que ajudará bastante ao professor na difícil hora da escolha.

Após a análise dos registros dos 27 aspectos positivos, percebeu-se que poderiam ser agrupadas em seis eixos: avaliação, orientação, clareza, organização, reflexão, análise e facilidade. Esses eixos encontram-se interligados, o que permitiu inferir a possibilidade de o instrumento auxiliar o professor na sua tarefa de escolha do livro didático.

Quanto aos aspectos negativos foram feitos 26 registros, dos quais são registrados três: 
R4 - Traz uma perspectiva ainda disciplinar, mas não é uma crítica ao instrumento, pois ele está de acordo com a perspectiva vigente, tanto nos livros didáticos quanto nos descritores de avaliação, projeto políticopedagógico e demais documentos do Colégio Pedro II.

R17 - A existência de um instrumento acaba por restringir o docente aos critérios contidos nele. Esse é o aspecto negativo.

R21 - Dada a especificidade pedagógica de cada ano escolar [...] sugiro a reflexão mais detida sobre a confecção de um questionário específico para cada ano escolar, com a análise dos objetivos pedagógicos e didáticos de cada ano. Seria interessante partir deste instrumento, aprofundado, para cada ano, os aspectos que aqui são abordados de forma mais genérica.

Esses registros se referem a pontos que não podem ser alterados no instrumento. Os comentários de R17 e R21 demandam um professor flexível, com abertura de pensamento, para poder usar o instrumento, o que vai ao encontro do projeto políticopedagógico, quando este documento afirma nas suas bases metodológicas que há "uma flexibilização dos conteúdos para atender aos interesses e diferenças que aparecem nos processos de cada turma (ou grupos de alunos) ou nas estratégias e técnicas do professor" (Colégio Pedro II, 2002, p. 70).

\section{Considerações finais}

Este estudo avaliativo teve por objetivo elaborar e validar um instrumento de avaliação que pudesse auxiliar os docentes na escolha dos livros didáticos oriundos do PNLD. Sabendo-se da importância do livro didático na prática docente, mostrou-se oportuna a validação e avaliação do instrumento pela equipe docente do campus Humaitá I.

O instrumento foi elaborado a partir de aspectos filosófico-educacionais propostos no projeto político-pedagógico do Colégio Pedro II (Colégio Pedro II, 2002). Além disso, foram considerados aspectos didático-metodológicos propostos no mesmo documento e obtidos na literatura e aspectos materiais retirados de um instrumento de avaliação de livros didáticos já validado (Silva, 2015).

A análise qualitativa referente aos registros dos professores sobre a escolha das três categorias - aspectos filosófico- educacionais, didático-metodológicos e materiais - e relativa aos respectivos indicadores dessas categorias, permite concluir que houve uma avaliação positiva desses elementos, a qual foi corroborada pela maioria dos comentários revelados nos questionários. Observou-se que houve reflexão por parte dos docentes sobre $o$ instrumento, fazendo com que sugerissem diversas modificações pertinentes, as quais foram acatadas pela autora e apresentadas no instrumento reformulado.

Cabe salientar que quando se avaliou a opinião dos respondentes sobre as condições do instrumento para auxiliar a escolha do livro didático, também ficou evidente a sua aceitação, pois encontrou-se 22 respostas em Sim e 7 em Parcialmente e nenhuma em Não.

Ao avaliar-se a adequação do instrumento ao objetivo para o qual foi proposto, considerando os padrões propostos: péssimo, fraco, regular, bom e excelente, também 
confirmou-se a sua adequação, com 17 marcações no padrão Excelente; 10 no padrão Bom; e apenas um em Regular e um em Fraco. O padrão Péssimo não recebeu nenhuma marcação.

A partir desses dados, conclui-se que o instrumento atende às necessidades do corpo docente qualificado para a avaliação dos livros didáticos. Assim, recomenda-se:

a) que se disponibilize o instrumento em uma plataforma online, tendo em vista a extensão do instrumento e a quantidade de livros a serem analisados;

b) que a escolha do livro didático com o uso do instrumento seja feita em equipe a fim de proporcionar debates e fomentar discussões acerca do livro a ser escolhido;

c) que se visualize a pontuação sugerida no instrumento para cada padrão como uma sugestão, não sendo necessária e obrigatória. Caberá à equipe escolar decidir quais os indicadores são os mais adequados e relevantes no momento da decisão em optar por um livro ou outro.

Finaliza-se este estudo entendendo-se que a construção coletiva da prática pedagógica é um aspecto fundamental para o momento da escolha do livro didático. 0 processo de validação e avaliação do instrumento proposto serviu como espaço de reflexão sobre os critérios que devem ser considerados em um livro didático, a partir da perspectiva dos docentes. Os comentários oriundos deste estudo avaliativo, críticas e sugestões, evidenciam o comprometimento do corpo docente com uma educação de qualidade, calcada no respeito às diferenças e na formação de indivíduos críticos, autocríticos e éticos.

\section{Referências}

BEZERRA, Holien Gonçalves. Em busca da qualidade: PNLD História - 1996-2004. In: SPOSITO, Maria Encarnação Beltrão (org.). Livros didáticos de história e geografia: avaliação e pesquisa. São Paulo: Cultura Acadêmica, 2006, p. 27-53.

BRASIL. Secretaria de Educação Fundamental. Parâmetros curriculares nacionais: introdução aos parâmetros curriculares nacionais. Brasília: MEC/SEF, 1997. Disponível em <http://portal.mec.gov.br/seb/arquivos/pdf/livro01.pdf>. Acesso em 28 mar. 2016.

BRASIL. Ministério da Educação. Guia de livros didáticos PNLD 2008: apresentação. Brasília: MEC, 2007. Disponível em < http://portal.mec.gov.br/seb/arquivos/pdf/Avalmat/pnldapres07.pdf>. Acesso em 28 mar. 2016.

BRASIL. Ministério da Educação. Programa Nacional do Livro Didático (PNLD). 2012. Disponível em <http://portal.mec.gov.br/index.phd?ltemid=668\&id=12391\&option=com_content\&view=article>. Acesso em 28 mar. 2016.

BRITTO, Tatiana Feitosa de. O livro didático: o mercado editorial. Brasília: Centro de Estudos da Consultoria do Senado, 2011.

CHOPPIN, Alain. História dos livros e das edições didáticas: sobre o estado da arte. Revista Educação e Pesquisa, São Paulo, v. 30, n. 3, 20044, p. 549-566.

COLÉGIO PEDRO II. Colégio Pedro II: projeto político-pedagógico. Brasília: Inep-MEC, 2002. Disponível em <http://www.publicacoes.inep.gov.br/portal/download/363>. Acesso em 20 mar. 2016. 
DI GIORGI, Cristiano et al. Uma proposta de aperfeiçoamento do PNLD como política pública: o livro didático como capital cultural do aluno/família. Ensaio: aval. pol. públ. Educ., Rio de Janeiro, v. 22, n. 85, 2014, p. 1027-1056.

FREITAG, Bárbara; COSTA, Wanderly F. da; MOTTA, Valéria. O livro didático em questão. São Paulo: Cortez, 1997.

HÖFLING, Eloisa de Mattos. Notas para discussão quanto à implementação de programas de governo: em foco o Programa Nacional do Livro Didático. Educação \& Sociedade, Campinas, ano 21, n. 70, 2000, p. 159-170.

LINO, Flavia Alves Machado. Avaliação do desempenho de leitura e escrita dos alunos dos $2^{\circ}$ e $3^{\circ}$ anos do Ensino Fundamental I do Colégio Pedro II Campus Humaitá l. Rio de Janeiro: Cesgranrio, 2015. 57f. Dissertação (mestrado Profissional em Avaliação), Fundação Cesgranrio.

MARTINS, Gilberto de Andrade. Sobre confiabilidade e validade. Revista Brasileira de Gestão e Negócios, São Paulo, v. 8, n. 20, 2006, p. 1-12. Disponível em <http://www.spell.org.br/documentos/ver/6471/sobre-confiabilidade-e-validade>. Acesso em 14 abr. 2016.

OLIVEIRA, João Paulo Teixeira de. A eficiência e/ou ineficiência do livro didático no processo de ensino-aprendizagem. CONGRESSO IBERO-AMERICANO DE POLITICA E ADMINISTRAÇÃO DA EDUCAÇÃO, 4, 2014. Anais ... Porto: Anpae, 2014.

SILVA, Jovana de Souza Nunes. Avaliação de aspectos pedagógicos de uma coleção de livros didáticos para os anos iniciais do ensino fundamental. Rio de Janeiro: Cesgranrio, 2015. 84f. Dissertação (mestrado Profissional em Avaliação), Fundação Cesgranrio.

SILVA, Marco Antônio. A fetichização do livro didático no Brasil. Educação e Realidade, Porto Alegre, v. 37, n. 3, 2012, p. 803-821. Disponível em <http://www.scielo.br/pdf/edreal/v37n3/06.pdf>. Acesso em 14 abr. 2016.

SILVA, Ezequiel Theodoro da. Livro didático: do ritual da passagem à ultrapassagem. Em Aberto, Brasília, ano 16, n. 69, 1996, p. 11-15. Disponível em <http://emaberto.inep.gov.br/index.php/emaberto/article/view/2062/2031>. Acesso em: 18 mar. 2016.

VEIGA, IIma Passos Alencastro. Educação Básica e Educação Superior: projeto político pedagógico. Campinas: Papirus, 2004.

VILARINHO, Lúcia Regina Goulart; SILVA, Jovana de Souza Nunes da. A avaliação do livro didático como instrumento de afirmação da autonomia da escola e de seus docentes. Meta: Avaliação, Rio de Janeiro, v. 7, n. 21, 2015, p. 403-428.

WORTHEN, Blaine R.; SANDERS, James R.; FITZPATRICK, Jody L. Avaliação de programas: concepções e práticas. São Paulo: Gente, 2004.

Sandra Regina Gonçalves Pimentel é professora no Colégio Pedro II, pedagoga pela UFRJ, especialista em Educação Especial pela UVA e mestre em avaliação pela Fundação Cesgranrio.

Endereço: Rua Domingos Ferreira, 41/1106 - 22050-011 - Rio de Janeiro - RJ Brasil.

E-mail: srgp26@hotmail.com. 
Lúcia Regina Goulart Vilarinho é professora adjunta no Programa de PósGraduação da Fundação Cesgranrio/RJ, mestre e doutora em educação pela UFRJ e pedagoga pela PUC-Rio.

Endereço: Rua Faro, 54/101 - 22461-020 - Rio de Janeiro - RJ - Brasil.

E-mail: luciagvilarinho@gmail.com.

Recebido em 19 de abril de 2017.

Aceito em 5 de agosto de 2017. 